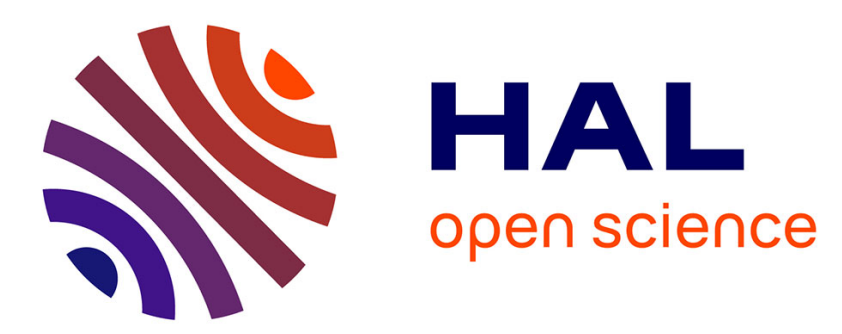

\title{
Tailoring interfacial bonding states of highly thermal performance diamond/Al composites: Spark plasma sintering vs. vacuum hot pressing
}

Zhanqiu Tan, Gang Ji, Ahmed Addad, Zhiqiang Li, Jean-François Silvain, Di Zhang

\section{To cite this version:}

Zhanqiu Tan, Gang Ji, Ahmed Addad, Zhiqiang Li, Jean-François Silvain, et al.. Tailoring interfacial bonding states of highly thermal performance diamond/Al composites: Spark plasma sintering vs. vacuum hot pressing. Composites Part A: Applied Science and Manufacturing, 2016, 91, Part 1, pp.9-19. 10.1016/j.compositesa.2016.09.012 . hal-01383372

\section{HAL Id: hal-01383372 \\ https://hal.science/hal-01383372}

Submitted on 2 Feb 2021

HAL is a multi-disciplinary open access archive for the deposit and dissemination of scientific research documents, whether they are published or not. The documents may come from teaching and research institutions in France or abroad, or from public or private research centers.
L'archive ouverte pluridisciplinaire HAL, est destinée au dépôt et à la diffusion de documents scientifiques de niveau recherche, publiés ou non, émanant des établissements d'enseignement et de recherche français ou étrangers, des laboratoires publics ou privés. 


\title{
Tailoring interfacial bonding states of highly thermal performance diamond/Al composites: Spark plasma sintering vs. vacuum hot
} pressing

\author{
Zhanqiu Tan ${ }^{\mathrm{a}}$, Gang Ji ${ }^{\mathrm{b}}$, Ahmed Addad ${ }^{\mathrm{b}}$, Zhiqiang Li ${ }^{\mathrm{a}}$, Jean-François Silvain ${ }^{\mathrm{c}}$, Di Zhang ${ }^{\mathrm{a}}$ \\ ${ }^{a}$ State Key Laboratory of Metal Matrix Composites, Shanghai Jiao Tong University, Shanghai 200240, \\ China \\ ${ }^{b}$ Unité Matériaux et Transformations, CNRS UMR 8207, Université Lille 1, Villeneuve d'Ascq 59655, \\ France \\ ${ }^{c}$ Institut de Chimie de la Matière Condensée de Bordeaux (ICMCB-CNRS), 87 Avenue du Docteur Albert \\ Schweitzer, 33608 Pessac Cedex, France
}

\begin{abstract}
Interfacial configurations of the diamond/Al composites fabricated by vacuum hot pressing (VHP) and spark plasma sintering (SPS) have been investigated to evaluate feasibility of both techniques for tailoring interfacial bonding states, namely non-bonded, diffusion-bonded, partially and fully reaction-bonded interfaces. Multiscale interfacial characterization reveals that the unique diffusionbonded interface at the micrometer scale, being very favorable for enhancing global thermal conductivity (TC), has been achieved by conventional VHP technique due to its large processing window and homogenous thermal field. Comparatively, micrometer-scale and, even macroscopic (radial and axial) thermal gradients can be inevitably generated during the SPS process in rapid heating-cooling mode. As a result, the mixed interfacial bonding states have always been introduced in the SPSed samples which reduce the effectiveness of TC enhancement. The formation mechanisms of nanoscale interfacial $\mathrm{Al}_{2} \mathrm{O}_{3}$ and $\mathrm{Al}_{4} \mathrm{C}_{3}$ at the diamond/Al interface are also discussed.
\end{abstract}

Keywords: Metal-matrix composites (MMCs); Thermal properties; Electron microscopy; Powder processing.

\section{Introduction}

In recently-published review papers [1], [2], the significant success achieved by spark plasma sintering (SPS) technique in the field of materials science and engineering has been timely summarized. The main advantages of SPS over conventional vacuum hot pressing (VHP) technique include a faster heating rate (up to $1000^{\circ} \mathrm{C} / \mathrm{min}$ ), a lower sintering temperature and a shorter holding time. As a result, the SPS process can result in ultrafine and/or nanoscale grain structures in final materials by effectively limiting recrystallization and grain coarsening. The SPS process also refers to pulsed electric current sintering since use of a pulsed dc current gets involved to activate the sintering process. Fundamental investigations have demonstrated that such an applied current has an important effect on (i) solid-state reactivity and mass transport [1], [2], [3], [4] and (ii) current and temperature distributions [1], [2], [5]. Regarding the latter, an electrically conducting sample, typically metals and alloys, carries almost all the current passing through and joule heating commences immediately inside the sample. Radial and axial temperature gradients can thus form, being closely related to heterogeneous current distribution, which contribute to microstructural and properties heterogeneity of the product. Such an intrinsic characteristic of the SPS process has been suggested by some authors as an ideal strategy to produce hetero- (or bimodal) nanostructured materials with enhanced mechanical properties such as in pure $\mathrm{Al}$ [6], pure Fe [7], oxide dispersion strengthened (ODS) FeAl [8], Al__ 5 at.\%Fe [9] alloys, Al__15 at.\%MgB composite [10], Ti_6AI_4 $\mathrm{V}$ alloy [11] and ODS ferritic steel [12]. However, understanding the properties gain by using the SPS process to produce metal matrix composites (MMCs) reinforced with 
ceramic particles for functional applications would not be straightforward. The main reason is that, compared with grain structure of the metal matrix, delicate interfacial configurations and bonding states play a more critical role to determine overall functional properties such as thermal conductivity (TC). The open question is then whether such temperature gradients generated during the SPS process are still beneficial in this case.

The necessary thermal properties of an ideal material candidate for heat dissipation applications in the microelectronic industry include a TC as high as possible and a low coefficient of thermal expansion (CTE), being compatible with that of electronic components $(<10 \mathrm{ppm} / \mathrm{K})$ [13]. Among all the developed composite materials, Al matrix composite reinforced with synthetic diamond particles (hereafter referred to as diamond/Al composite) has attracted considerable attention since its first discovery in 1993 [14]. On the one hand, the synthetic diamond has a high TC in the range $1000-2000 \mathrm{~W} / \mathrm{m} \mathrm{K}$ and a low CTE of 1-3 ppm/K, its price also continues to decrease with time down to around 300-1000 USD $/ \mathrm{kg}$ now. On the other hand, the Al matrix has a relatively high TC of around $240 \mathrm{~W} / \mathrm{m} \mathrm{K}$ among pure metals, and low density and price. Further, different from $\mathrm{Cu}$ matrix for example, interfacial bonding strength and interfacial thermal resistance (ITR) of the diamond/Al composite can be tailored by forming interfacial $\mathrm{Al}_{4} \mathrm{C}_{3}$ compound via the reaction between $\mathrm{Al}$ matrix and diamond particles. So far, the highest TCS of the VHPed diamond (50 vol.\%)/Al composite has reached around $500 \mathrm{~W} / \mathrm{m} \mathrm{K} \mathrm{[15]} \mathrm{and} 600 \mathrm{~W} / \mathrm{m} \mathrm{K}$ by using $\mathrm{W}$-coated diamond particles [16]. The SPS method has been used but failed to compete with VHP technique to produce samples with comparable TCs. For example, the SPSed diamond (45 vol.\%)/AI composite has the highest TC of around $400 \mathrm{~W} / \mathrm{m} \mathrm{K}$ [17], while the TC of the SPSed diamond (50 vol.\%)/Al composite can only extend from 310 to around $490 \mathrm{~W} / \mathrm{m} \mathrm{K}$ by using Ti-coated diamond particles [18]. Thus, these facts call in question whether SPS is an appropriate manufacturing process to obtain tailored diamond/Al interfaces. To answer the question, SPSed samples where produced and the resulting interface structure was investigated at the micro- and the nanoscale. However, it is a common practice to examine fracture surface for roughly examining bonding states of the diamond/Al interface since it is difficult to equally polish hard diamond particles and soft Al matrix. Although chemical and electrochemical etching methods can reveal certain interfacial reaction products like $\mathrm{Al}_{4} \mathrm{C}_{3}$ by extracting the Al matrix [19], they cannot reserve true interfacial states and terribly wash off nanoscale interfacial features without strong bonding with the diamond surface. To overcome these problems, a triple ion beam (TIB) cutting technique has been successfully applied to acquire a flat surface without additional artifacts [20].

It is well-known that interfacial bonding states, namely non-bonded, diffusion-bonded and reactionbonded interfaces, can have a significant impact on global TC of MMCs whatever the employed VHP or SPS fabrication techniques. It has previously been demonstrated in VHPed SiC/Al composites that the formation of the nanoscale diffusion-bonded interface is the most favorable for TC enhancement [21]. This experimental result is also in good agreement with our predictive model since it is expected that the diffusion-bonded interface can provide not only necessary bonding strength but also low ITR [22]. Hence, in this work in-depth interfacial characterization of the SPSed and VHPed diamond (40 and 50 vol.\%)/Al composites has been carried out at length scales from the macro to nanoscale in order to evaluate the feasibility of SPS and VHP techniques to tailor such a bonding state. The TIB technique has been used to prepare nearly-perfect surface of samples to make true interfacial characterization possible at the micrometer scale and facilitate site-specific sample preparation by focus ion beam (FIB) [20]. Special attention has been paid to shedding light on the effect of thermal gradients spontaneously generated during the SPS process on interfacial configurations and bonding states of the diamond/Al composites.

\section{Experimental procedures}

\subsection{Starting materials and powder processing}


A synthetic diamond powder (Type HWD40 and average particle size of $200 \mu \mathrm{m}$ ) was purchased from Henan Huanghe Whirlwind International Co. Ltd., China. A pure Al powder (around $99.8 \%$ in purity) having the particle size in the range 75-105 $\mu \mathrm{m}$ was used as matrix material. Detailed characteristics of these starting powders such as chemistry, morphology and nitrogen concentration have been described elsewhere [15].

A model 2040 SPS apparatus (Sumitomo Coal and Mining Co., Ltd.) was used to sinter pure Al and diamond (40 and 50 vols.\%)/Al composites. Vacuum level of sample chamber was pumped down to around $6.67 \mathrm{~Pa}$ (i.e. $5 \times 10^{-2}$ Torr) before heating. Constant uniaxial pressure of $50 \mathrm{MPa}$ was kept during heating and cooling stages and holding time of $5 \mathrm{~min}$ was used for all the SPS processes. Processing condition has been optimized by adjusting sintering temperature in the range $540-560{ }^{\circ} \mathrm{C}$ in terms of relative density of sintered pure $\mathrm{Al}$ as a reference. Temperature was measured by a k-type thermocouple placed in a horizontal hole in the mi-depth of the graphite die (distance to sample edge of around $5 \mathrm{~mm}$ ). Temperature differences between the sintered samples and the measured temperatures were estimated to be in the range $100-120^{\circ} \mathrm{C}$ since no Al seepage was observed. Disk dimension of the sintered sample was $\varnothing 10 \times 3 \mathrm{~mm}$.

During VHP process, uniaxial pressure of $67 \mathrm{MPa}$ was applied and sintering temperature was set to $650^{\circ} \mathrm{C}$. More information concerning preparation details of VHPed diamond/Al composites can be found in [15], [16].

\subsection{Characterization of microstructure and TC}

X-ray diffraction (XRD) measurement was performed on a D/max-2550 X-ray diffractometer, operated at $35 \mathrm{kV}$ and $200 \mathrm{~mA}$, by using $\mathrm{Cu} \mathrm{K}_{\alpha}$ radiation $(\lambda=0.15406 \mathrm{~nm}) .2 \theta$ scans were performed between $30^{\circ}$ and $80^{\circ}$ with a scan speed of $4^{\circ} / \mathrm{min}$. Careful scanning was performed in the angle range of $30-37^{\circ}$ with a step size of $0.01^{\circ}$ in order to detect the presence of $\mathrm{Al}_{4} \mathrm{C}_{3}$ (JCPDS file 35-0799). Composite samples were cut by the TIB technique and characterized using a HITACHI S-4700 scanning electron microscope (SEM) equipped with a field emission gun (FEG) and a Noran energy dispersive X-ray (EDX) spectrometry system. A STRATA DB 235 dual beam FIB instrument was employed to prepare specimens having diamond/Al interface of interest for transmission electron microscopy (TEM). A Philips CM30 microscope, operated at $300 \mathrm{kV}$ and equipped with a Nanomegas 'Spinning Star' precession unit and a Noran EDX spectrometry system, was used for TEM characterization. Lattice images were obtained using an FEI Tecnai G2 FEG microscope, operated at 200 kV.

Relative density $(\rho)$ of the sintered samples was measured by the Archimedes' method. Thermal diffusivity $(\alpha)$ was measured by laser flash technique using a Netzsch LFA447 thermal constant analyzer in the Applied Laboratory of Netzsch Company, Shanghai China. Each $\alpha$ value was an average of three measurements and the standard deviation was $2 \%$. TC $(\lambda)$ of the composites was calculated using the following equation $\lambda=\alpha \rho C_{p}$, where $\rho$ and $C_{p}$ represent density and specific heat capacity, respectively. $C_{p}$ of the diamond/Al composite was calculated by the rule of mixtures using $C_{p}$ values of the constituents: $512 \mathrm{~J} / \mathrm{kg} \mathrm{K}$ for diamond particle and $890 \mathrm{~J} / \mathrm{kg} \mathrm{K}$ for Al matrix [23].

\section{Results and discussion}

\subsection{Measurement of relative density and TC}

As shown in Fig. 1a, at the given uniaxial pressure of $50 \mathrm{MPa}$ and holding time of 5 min use of the selected SPS temperature range $\left(540-560^{\circ} \mathrm{C}\right)$ allows the relative densities of all the pure Al samples to reach higher than $96 \%$ and as high as of around $99 \%$ at $560{ }^{\circ} \mathrm{C}$. Application of these parameters to the diamond/Al composites results in generally lower relative densities than those of the pure Al matrix. In 
the case of the diamond $(40 \mathrm{vol} . \%) / \mathrm{Al}$ composite, the relative density increases with sintering temperature from $87 \%$ at $540{ }^{\circ} \mathrm{C}$ up to around $97 \%$ at $560{ }^{\circ} \mathrm{C}$. Further increase of the diamond volume fraction to $50 \%$ in the composite is clearly harmful for densification whatever the sintering temperatures.
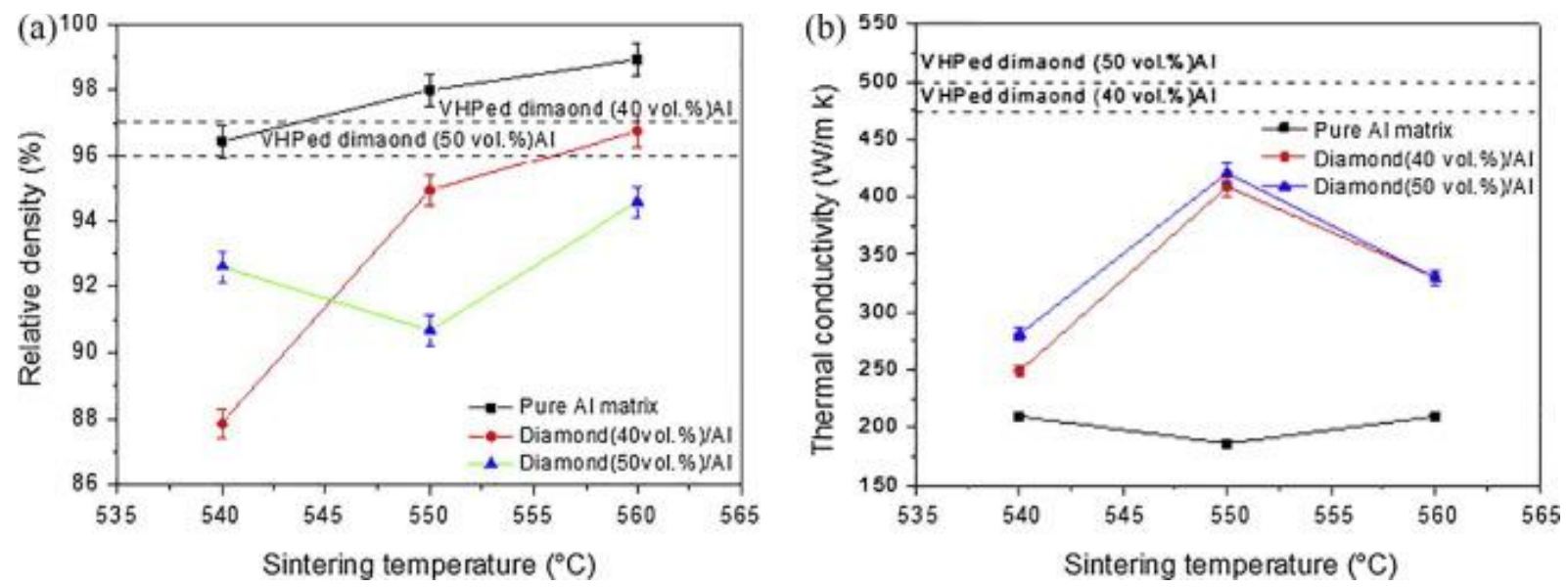

Fig. 1. (a) Relative density and (b) TC as a function of SPS sintering temperatures at 540 , 550 and $560{ }^{\circ} \mathrm{C}$ for pure Al matrix and diamond/Al composites with 40 and 50 vol.\% diamond particles. Dash lines in (a) and (b) indicate relative density and TC of the VHPed counterparts for comparison, respectively. (For interpretation of the references to color in this figure legend, the reader is referred to the web version of this article.)

The relative densities of the diamond (50 vol.\%)/Al samples are lower than $95 \%$ and their evolution as a function of temperature is different compared with those of the others to show bad reproducibility. Similar non-reproducibility previously observed in SPSed FeAl alloys is explained by uncertainty of temperature measurement and surface properties of starting powders (no suitable pre- and in-situ degassing treatments) [24]. It has also been reported that asymmetric positioning of plungers in the die is another reason conducting heterogeneity of density and microstructure in samples [5].

Fig. $1 \mathrm{~b}$ plots the corresponding TC values of the studied samples processed at 540,550 and $560{ }^{\circ} \mathrm{C}$. The TCS of the SPSed pure Al samples are around $200 \mathrm{~W} / \mathrm{m} \mathrm{K}$ being independent of sintering temperature despite high relative density. This suggests that grain structure of pure Al does not significantly affect global TC since it is expected that grain coarsening can occur at the high temperature. However, increase of sintering temperature has a significant impact on the TCs of the diamond/Al composites, which increase to reach the maximal values from 540 to $550{ }^{\circ} \mathrm{C}$, and decrease to around $330 \mathrm{~W} / \mathrm{m} \mathrm{K}$ for both at $560{ }^{\circ} \mathrm{C}$. The highest TCs of the composites having the diamond volume fractions of 40 and $50 \%$ are 408 and $420 \mathrm{~W} / \mathrm{m} \mathrm{K}$, respectively. For comparison, the relative densities and TCS of the VHPed diamond/Al composites processed in the optimized conditions (i.e. $67 \mathrm{MPa} / 650^{\circ} \mathrm{C} / 90 \mathrm{~min}$ [15]), are also given in Fig. 1. It is interesting to indicate that only the SPSed diamond (40 vol.\%)/Al sample sintered at $560{ }^{\circ} \mathrm{C}$ has the relative density $(96.7 \%)$ being comparable to that of the VHPed counterpart $(97 \%)$, while its TC of around $330 \mathrm{~W} / \mathrm{m} \mathrm{K}$ is much lower. Note also that the TC of the VHPed diamond (40 vol.\%)/Al sample is around $475 \mathrm{~W} / \mathrm{m} \mathrm{K}$ which is close to the highest TC value predicted by differential effective medium (DEM) scheme [15]. The similar and high relative densities indicate, at least, achievement of good physical bonding at the diamond/Al interface in both samples. In other words, the observed TC difference in the VHP and SPS cases (475 vs. $330 \mathrm{~W} / \mathrm{m} \mathrm{K}$ ) mainly depend on interfacial chemical nature and bonds, and related formation of the diffusion or reaction bonded interfacial states. Hence, interfacial configurations of the SPSed and VHPed diamond (40 vol.\%)/AI composites have been characterized from the macro- down to nanoscales in order to clarify the sintering mechanisms involved in the VHP and SPS processes. 


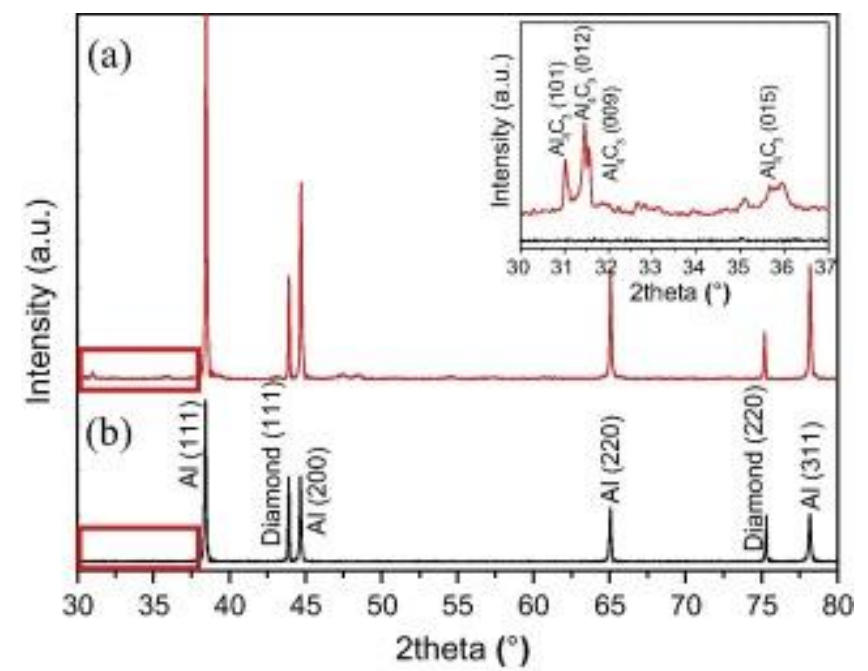

Fig. 2. XRD patterns of the diamond (40 vol.\%)/Al composites sintered by (a) SPS and (b) VHP techniques; inset highlights the main diffracted peaks corresponding to $\mathrm{Al}_{4} \mathrm{C}_{3}$ in the box areas in (a) and (b). (For interpretation of the references to color in this figure legend, the reader is referred to the web version of this article.)

\subsection{Multiscale interfacial characterization by XRD, SEM and TEM}

The XRD patterns of both VHPed and SPSed samples (Fig. 2) show the diffracted peaks of Al and diamond, while the diffracted peaks corresponding to $\mathrm{Al}_{4} \mathrm{C}_{3}$ are only detected in the SPSed sample. This result indicates that the interfacial reaction to introduce $\mathrm{Al}_{4} \mathrm{C}_{3}$ at the diamond/Al interface is more pronounced in the SPSed than VHPed samples. It also excludes the possibility of excessive interfacial reaction in the characterized VHPed sample. The SEM images of the VHPed diamond (40 vol.\%)/AI composite (Fig. 3) show that the diamond particles and Al matrix have equally been polished where the diamond particles closely stick to the Al matrix in the polished surface to show the good bonding state. The zoom-in images in Fig. 3b-d further reveal that the diamond/Al interfaces are tightly adhered without any defects and interfacial products like $\mathrm{Al}_{4} \mathrm{C}_{3}$. It is well-known in diamond/Al composite processed by liquid infiltration that dissolution of carbon atoms at the $\left\{\begin{array}{lll}1 & 0 & 0\end{array}\right\}$ surface of diamond crystal is much easier than those at the $\left\{\begin{array}{lll}1 & 1 & 1\end{array}\right\}$ surface due to its weak twofold bonding state [25], [26]. As a result, platelet-like $\mathrm{Al}_{4} \mathrm{C}_{3}$ has often been observed to nucleate and grow at the diamond $\mathrm{A}_{\{00\}} / \mathrm{Al}$ interface, while the diamond ${ }_{\{111\}} /$ Al one can still remain unattached by liquid $\mathrm{Al}$ [25], [26]. By using the solid-state VHP technique in this work as shown in Fig. 4, complex interfacial features along with $\mathrm{Al}_{4} \mathrm{C}_{3}$ (arrowed) are present in the Al matrix next to the diamond $d_{\{100\}} / A$ interface of the VHPed sample. A closer look at a typical area of this interface (Fig. 5) reveals an $\mathrm{Al} / \mathrm{Al}_{2} \mathrm{O}_{3} / \mathrm{Al}_{4} \mathrm{C}_{3} /$ diamond ${ }_{\{100\}}$ multi-interface and the

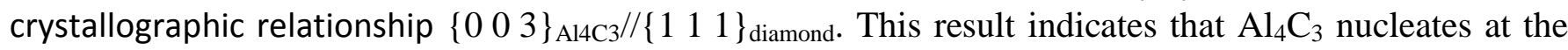
$\left\{\begin{array}{lll}1 & 1 & 1\end{array}\right\}$ facet of the $\left(\begin{array}{lll}1 & 0 & 0\end{array}\right)$ diamond surface. Contrast to this, Fig. 6 a shows a sharp diamond $\{111\} / \mathrm{Al}$ interface homogenously covered by an $\mathrm{Al}_{4} \mathrm{C}_{3}$ interfacial layer where individual $\mathrm{Al}_{4} \mathrm{C}_{3}$ can be further extended into the $\mathrm{Al}$ matrix. The thin layer has the thickness of around $10 \mathrm{~nm}$ and the relationship $\left\{\begin{array}{lll}0 & 0 & 3\end{array}\right\}_{\mathrm{A} \mid 4 C 3} / /\left\{\begin{array}{lll}1 & 1 & 1\end{array}\right\}_{\text {diamond }}$ is also confirmed since the measured spacing of $\left\{\begin{array}{lll}0 & 0 & 6\end{array}\right\}_{\mathrm{A} \mid 4 C 3}$ planes $(d=0.416 \mathrm{~nm})$, being parallel to $\left\{\begin{array}{lll}1 & 1 & 1\end{array}\right\}_{\text {diamond, }}$, is exactly twice smaller than that of $\left\{\begin{array}{lll}0 & 0 & 3\end{array}\right\}_{\mathrm{Al} 4 \mathrm{C} 3}$ planes $\left(\mathrm{d}=0.832 \mathrm{~nm}\right.$ ) (Fig. 6b). Despite no $\mathrm{Al}_{4} \mathrm{C}_{3}$ detectable by XRD (Fig. 2), formation of the nanoscale $\mathrm{Al}_{4} \mathrm{C}_{3}$ at both $\left\{\begin{array}{lll}1 & 0 & 0\end{array}\right\}$ and $\left\{\begin{array}{lll}1 & 1 & 1\end{array}\right\}$ surfaces of diamond can mean the beginning of reaction bonded interface. The heterogeneous interfacial features mainly originate from the different properties of the $\left\{\begin{array}{lll}1 & 0 & 0\end{array}\right\}$ and $\left\{\begin{array}{lll}1 & 1 & 1\end{array}\right\}$ surfaces of diamond. In general, the results of XRD, SEM and TEM indicate that the VHP technique performed in thermodynamically equilibrium conditions provides a large processing window and homogenous temperature field enabling to tailor the 'clean' diffusion-bonded interface at the micrometer scale but not at the nanoscale. 

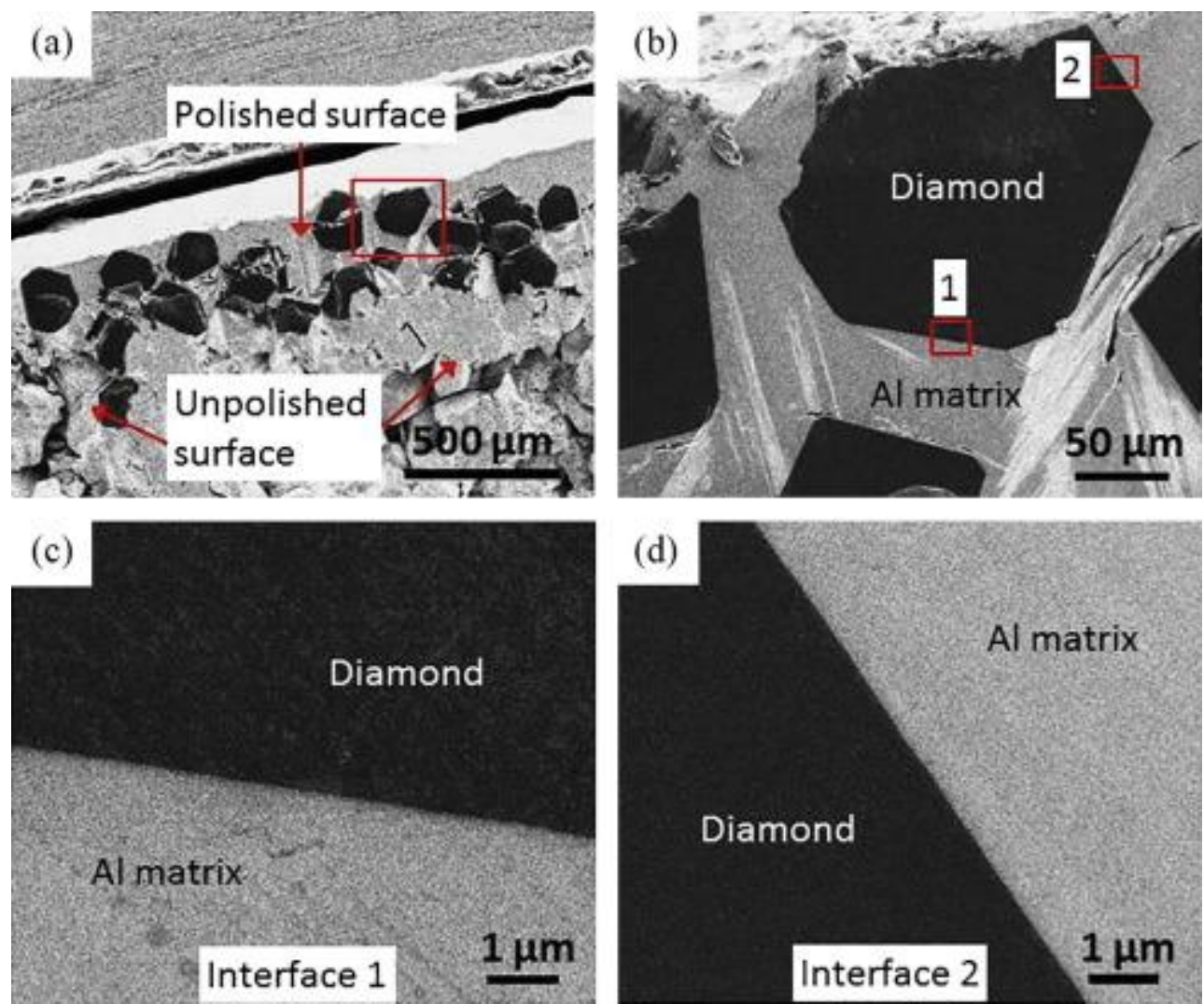

Fig. 3. SEM images showing (a) an overview of polished and unpolished surfaces of the VHPed diamond (40 vol.\%)/Al composite sample, $(b)$ diamond/Al interfaces in the polished flat surface selected by a rectangle box given in (a) and (c) and (d) zoom-in of 'clean' diamond/Al interfaces in boxes numbered by Nos. 1 and 2 shown in (b). (For interpretation of the references to color in this figure legend, the reader is referred to the web version of this article.)

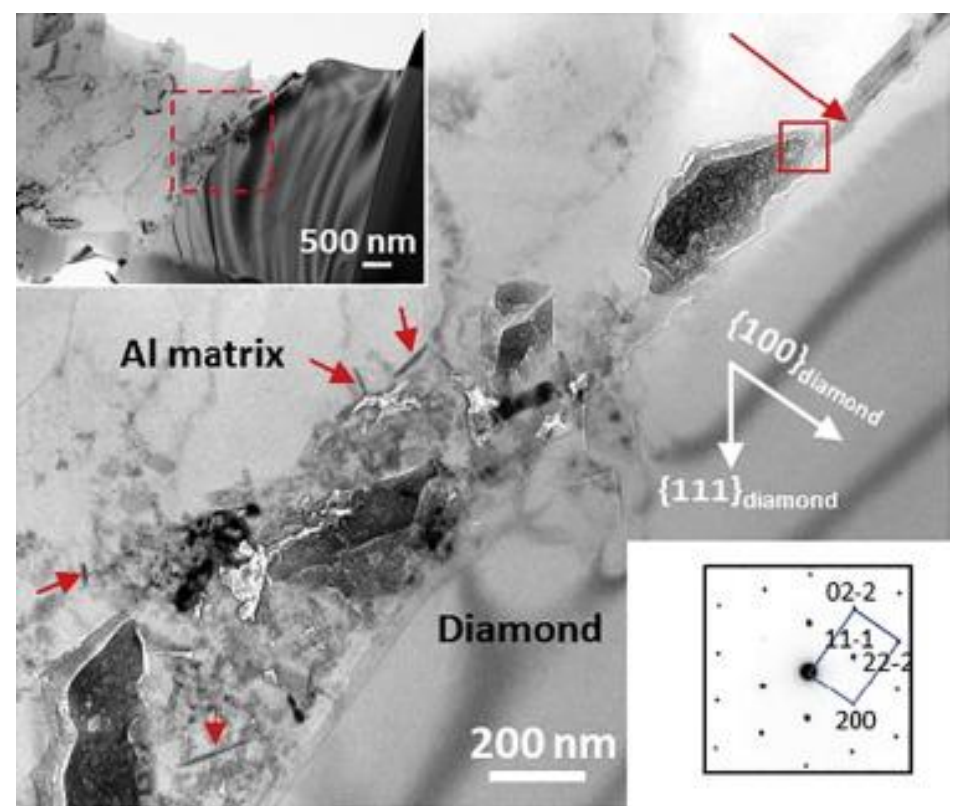

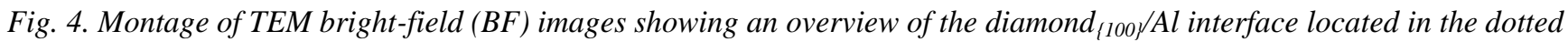
line box in the as-prepared FIB sample (see inset), inset also gives the [0 1 1] ZAP of diamond side with adjusted orientation relationship with respect to image. Note that plate-like $\mathrm{Al}_{4} \mathrm{C}_{3}$ compounds are arrowed and interfacial area in box is further analyzed. (For interpretation of the references to color in this figure legend, the reader is referred to the web version of this article.) 
In the case of the SPSed sample, the SEM image of the polished surface in Fig. 7a shows first two imprints where diamond particles have been attacked away during the TIB preparation process due to locally poor interfacial bonding. Second, different from the overall 'clean' diamond/Al interfaces in the VHPed sample, the three different types of interfacial configurations including interfacial factures (Fig. 7b), interfacial products (Fig. 7c) and 'clean' interface (Fig. 7d) are distinguished at this micrometer scale. As also shown in Fig. 7c, the platelet-like interfacial products having the length of about several micrometers and their nature has been identified by SEM/EDX analysis to corresponding to $\mathrm{Al}_{4} \mathrm{C}_{3}$. Besides, there are finer interfacial particles having the size in the sub-micrometer range which cannot be identified by SEM. Their nature has further been confirmed by electron diffraction and TEM/EDX (see Fig. 8) to be $\mathrm{Al}_{2} \mathrm{O}_{3}$ and $\mathrm{Al}_{4} \mathrm{C}_{3}$ interfacial particles. As shown in Fig. 8c, the $\left\{\begin{array}{lll}0 & 0 & 3\end{array}\right\}_{\mathrm{Al} 4 \mathrm{C} 3} / /\left\{\begin{array}{llll}1 & 1 & 1\end{array}\right\}_{\text {diamond }}$ relationship is again determined in the SPSed sample.
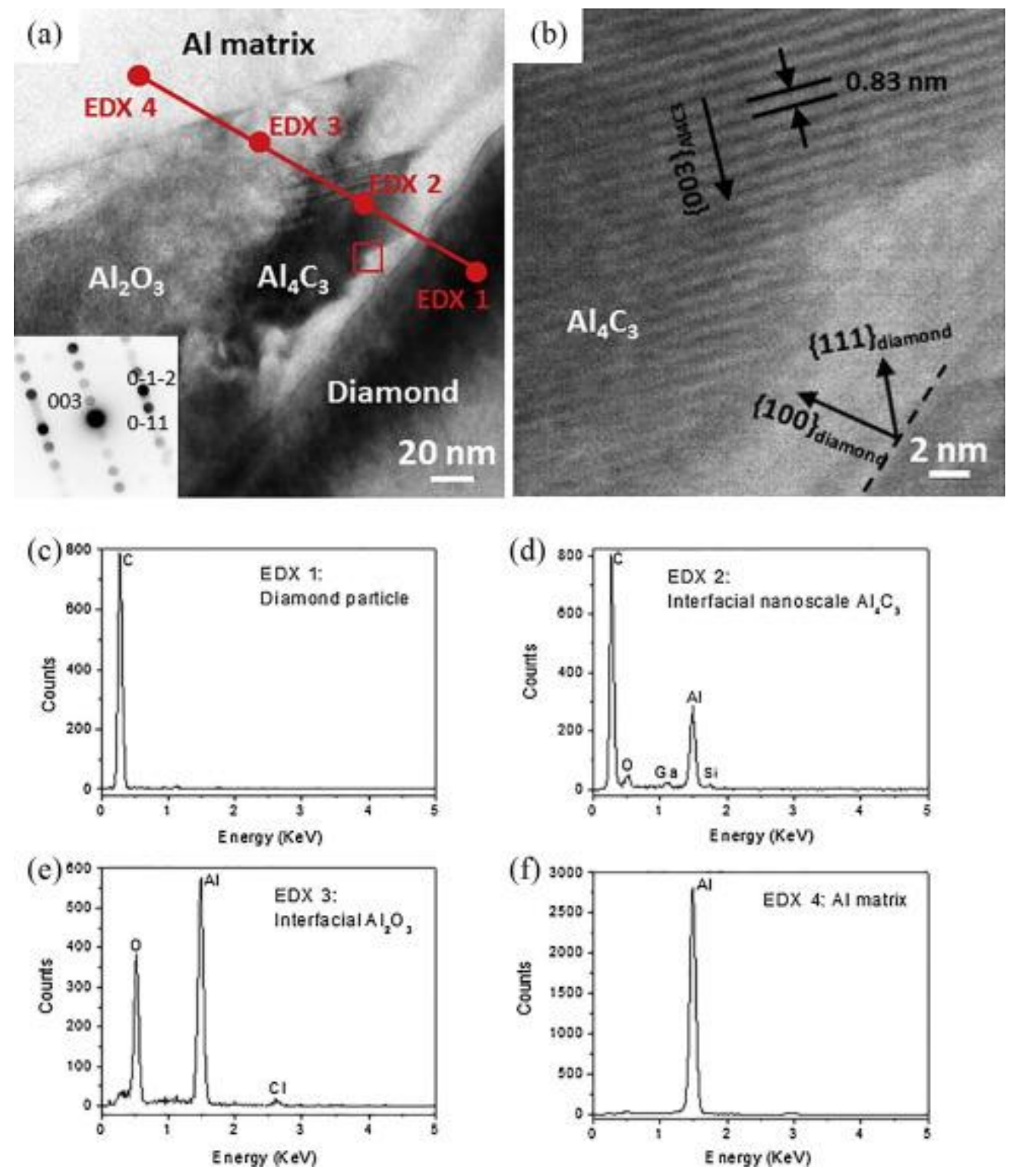

Fig. 5. (a) TEM BF image highlighting the interfacial area in box shown in Fig. 4, (b) zoom-in lattice image of the area in box shown in (a), (c)-(f) typical EDX spectra recorded from the diamond, interfacial $\mathrm{Al}_{4} \mathrm{C}_{3}$ and $\mathrm{Al}_{2} \mathrm{O}_{3}$ and Al matrix. Inset in (a) is the $\left[\begin{array}{lll}1 & 0 & 0\end{array}\right] \mathrm{ZAP}$ of $\mathrm{Al}_{4} \mathrm{C}_{3}$ with adjusted orientation relationship with respect to image. (For interpretation of the references to color in this figure legend, the reader is referred to the web version of this article.)

\subsection{Correlation of characterized interfacial configurations with global TCs}

Understanding heat conduction mechanism across the diamond/metal interface is the key issue in order to reduce ITR and, in turn, to further develop high thermal performance composite materials such as the 
diamond/Al composite. In a very general sense, the expected ideal interfacial state for minimizing ITR is acquisition of the diffusion-bonded interface at the nanoscale as long as sufficient wettability can be ensured and chemical bonding due to excessive interfacial reaction to form $\mathrm{Al}_{4} \mathrm{C}_{3}$ (i.e. reaction-bonded) can be effectively limited [22], [25], [27], [28], [29]. Fig. 9 schematically depicts the possible diamond/Al interface evolution in thermodynamic equilibrium, such as during the VHP process, by considering the different characteristics of the $\left\{\begin{array}{lll}1 & 0 & 0\end{array}\right\}$ and $\left\{\begin{array}{lll}1 & 1 & 1\end{array}\right\}$ diamond surfaces [25]. With increase of sintering temperature the pathway can be non-bonded (i.e. featured by low density), 'clean' quasi- diffusion bonded, partially and finally full reaction-bonded interfaces. As evidenced by SEM in Fig. 3, the optimized VHP conditions at best provide feasibility to tailor the quasi- diffusion-bonded diamond/Al interface at the micrometer scale. However, at the finer scales as highlighted by TEM observations (Fig. 4, Fig. 5, Fig. 6), the very different interfacial configurations are still observed at the diamond $\{100\} / \mathrm{Al}$ and

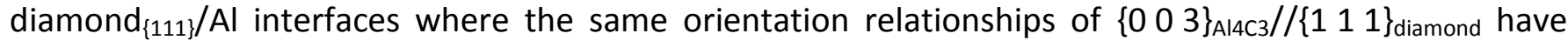
been determined, being in agreement with the results published in [26], [30]. It has been reported that the $\mathrm{Al}_{4} \mathrm{C}_{3}$ crystals nucleate and grow on pits or high density $\left\{\begin{array}{lll}1 & 1 & 1\end{array}\right\}$ facets initially formed on the $\left\{\begin{array}{lll}1 & 0 & 0\end{array}\right\}$ surface of diamond under the combined effects of surface reaction and reconstruction, while they nucleate at active edges of surface steps and grow to lay upon the $\left\{\begin{array}{lll}1 & 1 & 1\end{array}\right\}$ surface [30]. The special morphology of the single crystal $\mathrm{Al}_{4} \mathrm{C}_{3}$ layer with a large aspect ratio over at least 50 (see Fig. 6) indicates its low nucleation rates and lateral growth dominantly controlled by surface diffusion of carbon atoms dissolved from the $\left\{\begin{array}{lll}1 & 1 & 1\end{array}\right\}$ surface of diamond. This is because the diffuse interface migrates much faster than the flat interface under low growth driving forces (e.g., at the low melting temperature) [30], [31].

Further, it is worth discussing the possible roles of interfacial $\mathrm{Al}_{2} \mathrm{O}_{3}$ particles since it is an unavoidable issue in VHP and SPS processing of the Al matrix composites as revealed in this work (Fig. 4, Fig. 5, Fig. 8), in the $\mathrm{W}$ coated diamond/Al [27] and the carbon fiber/Al composites [32]. The origins of $\mathrm{Al}_{2} \mathrm{O}_{3}$ segments (or agglomerations) accumulated surrounding the diamond/Al interface result from breakdown of the $\mathrm{Al}_{2} \mathrm{O}_{3}$ skin of as-received $\mathrm{Al}$ powder and possible oxygen gettering during the sintering process. The fact that the interfacial $\mathrm{Al}_{4} \mathrm{C}_{3}$ formed at the $\left\{\begin{array}{lll}1 & 0 & 0\end{array}\right\}$ and $\left\{\begin{array}{lll}1 & 1 & 1\end{array}\right\}$ surfaces of diamond due to effective diffusion of carbon into aluminum matrix indicates that the presence of $\mathrm{Al}_{2} \mathrm{O}_{3}$ segments do not act as an overall diffusion barrier. Nevertheless, the size and quantity of nanosized $\mathrm{Al}_{2} \mathrm{O}_{3}$ particles in the Al matrix can have an effect on local interstitial lattice diffusion of carbon atoms and thus on nucleation and growth of $\mathrm{Al}_{4} \mathrm{C}_{3}$ compounds [27]. As given in Table 1, the $\mathrm{TC}$ of crystallized $\mathrm{Al}_{2} \mathrm{O}_{3}$ is $36 \mathrm{~W} / \mathrm{m} \mathrm{K}$, while that of its amorphous counterpart is as low as $1.5-1.8 \mathrm{~W} / \mathrm{m} \mathrm{K}$. Fig. 10 plots the calculated ITR as a function of (crystallized and amorphous) $\mathrm{Al}_{2} \mathrm{O}_{3}$ interlayer thickness in the $\mathrm{Al} / \mathrm{Al}_{2} \mathrm{O}_{3} /$ diamond multiinterface according to the acoustic mismatch model (AMM) [22]. This theoretical result indicates that compared with the pure diamond/Al interface the additional ITR is only introduced by the presence of the crystallized $\mathrm{Al}_{2} \mathrm{O}_{3}$ interlayer when its thickness is higher than $500 \mathrm{~nm}$. However, in the case of the amorphous $\mathrm{Al}_{2} \mathrm{O}_{3}$ interlayer, the ITR increases much quicker and the additional ITR becomes detectable at the interlayer thickness of around $30 \mathrm{~nm}$. Hence, as long as the continuous amorphous $\mathrm{Al}_{2} \mathrm{O}_{3}$ skin of the starting Al powder is broken down and crystallized in the VHPed and SPSed samples, its harmful effects on ITR and interfacial bonding are limited. 


\section{(a)}

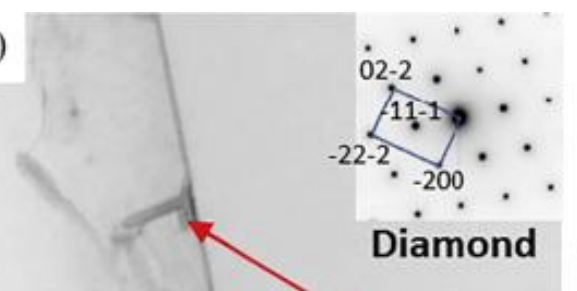

(b)

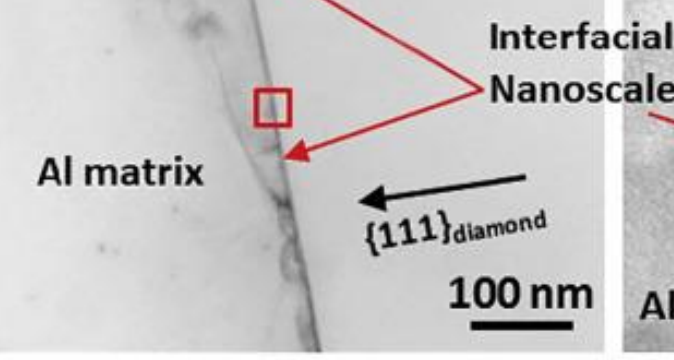

(c)

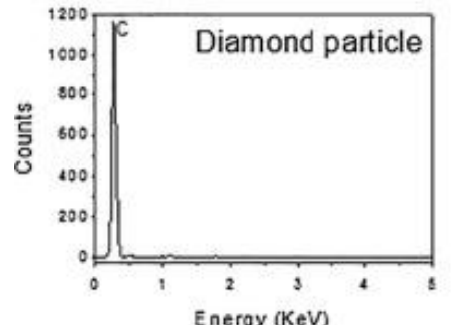

(d)

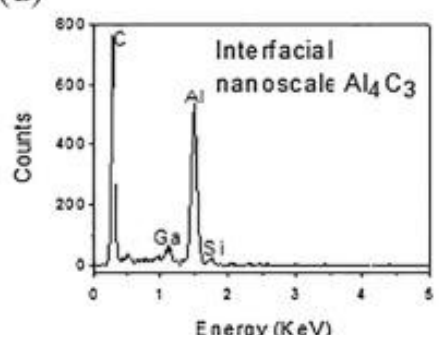

\section{Diamond}

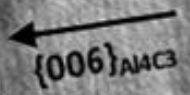

[111 diamond

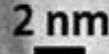

(e)

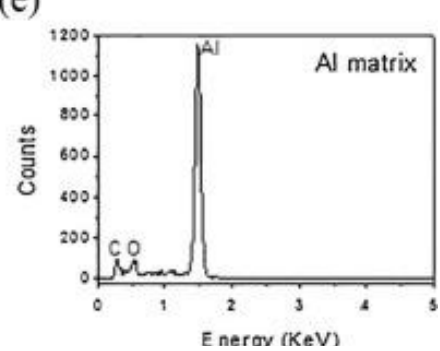

Fig. 6. (a) TEM BF image showing a straight diamond ${ }_{\{111} / \mathrm{Al}$ interface of the VHPed diamond (40 vol.\%)/Al composite in the as-prepared FIB sample, (b) zoom-in lattice image of interfacial area in the box in (a) showing an $\mathrm{Al}_{4} \mathrm{C}_{3}$ interfacial layer having the thickness of around $10 \mathrm{~nm},(\mathrm{c}),(\mathrm{d})$ and (e) typical EDX spectra recorded from the diamond, interfacial $\mathrm{Al}_{4} \mathrm{C}_{3}$ and $\mathrm{Al}$ matrix, respectively. Inset in (a) is the [0 1 1] ZAP of diamond side with adjusted orientation relationship with respect to image. (For interpretation of the references to color in this figure legend, the reader is referred to the web version of this article.)

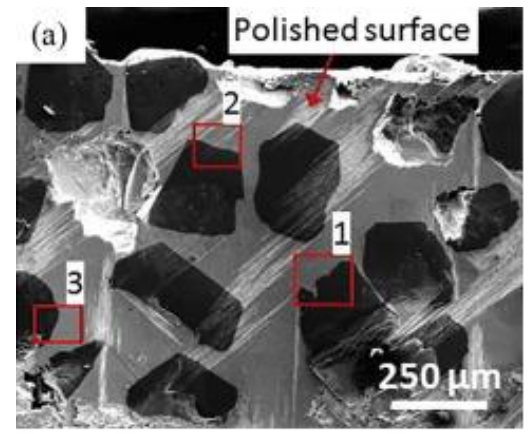

(c)
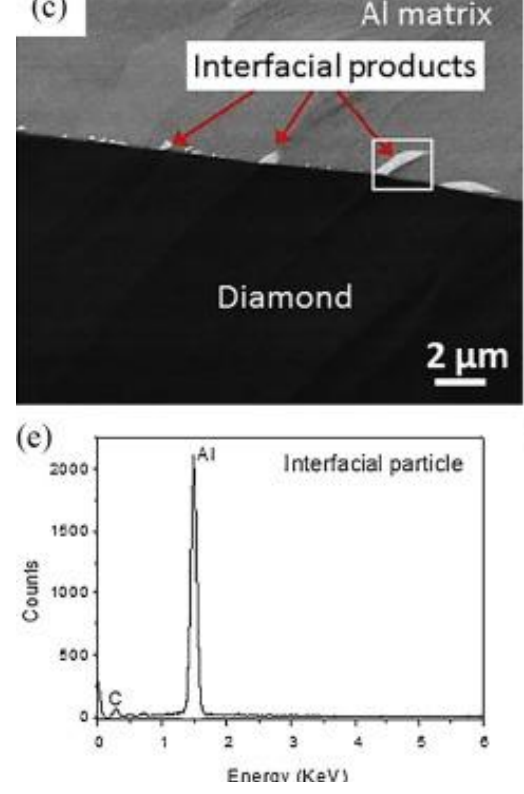
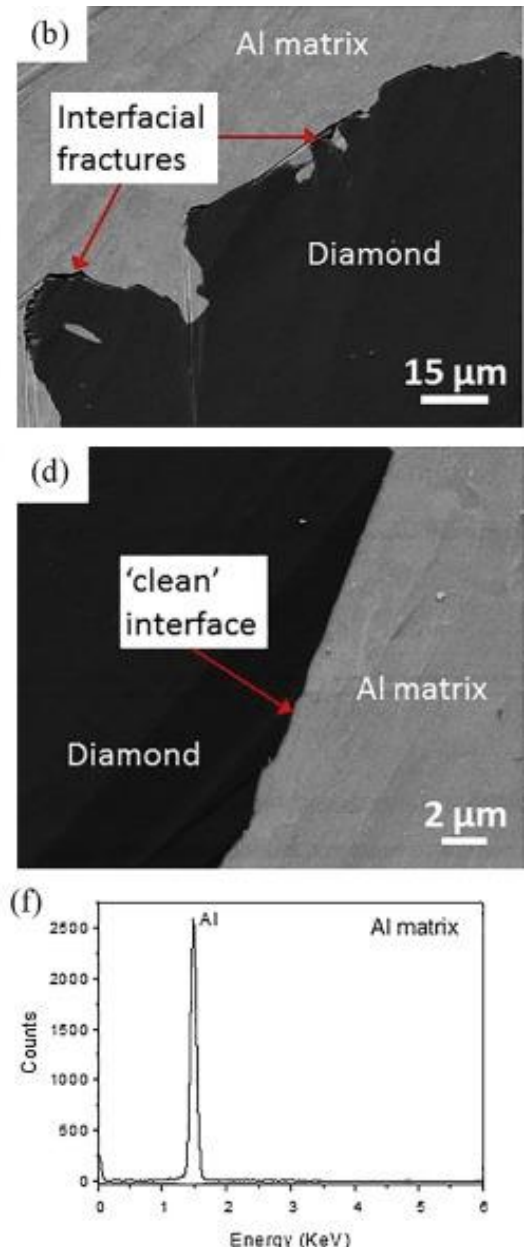
Fig. 7. SEM images showing (a) an overview of polished surface of the SPSed diamond (40 vol.\%)/Al composite sample containing mixed interfacial features, (b) fracture interface in the box No. 1 shown in (a), (c) interface with visible reaction products in the box No. 2 shown (a) and (d) 'clean' interface in the box No. 3 shown in (a); (e) and (f) are EDX spectra of the platelet-like interfacial particle in the box shown in (c) and the Al matrix next to this particle, respectively. (For interpretation of the references to color in this figure legend, the reader is referred to the web version of this article.)

Different from the VHP case, despite the optimized conditions for high densification, the SPS technique shows no potential to acquire the unique interfacial state (Fig. 7). Diamond is an electrical insulator and its electrical resistivity is on the order of $10^{11}$ to $10^{18} \Omega \mathrm{m}$ [41], while that of the pure Al matrix is around $2.655 \times 10^{-8} \Omega \mathrm{m}$ at room temperature [42]. As a result, during the SPS process all the current is only carried by electrically conducting Al matrix and graphite die. At the beginning of sintering, necks bridging the Al powder particles are quickly formed with the aid of the pulsed direct current due to higher local density of electrical current. As such, local temperature surrounding the necks becomes higher than in the rest of powder particles. The applied uniaxial pressure associated with local joule heating further enable the necks to grow and soften to have a fast sintering to reach full density [1], [2]. Hence, it is believed that diamond particles next to the necks in the Al matrix reaching a higher temperature trigger interfacial reaction to form the reaction-bonded interface, while those away from the neck areas experience lower temperature to form the diffusion-bonded or non-bonded interfaces. Rapid cooling applied during the SPS process is also susceptible to introduce de-bonding, if local bonding strength is insufficient at the diamond/Al interface. In terms of the sintering mechanisms related to local (radial and axial) temperature gradients, the mixed interfacial state including the non-bonded, 'clean' quasidiffusion-bonded and reaction-bonded interfaces has finally been introduced in the SPSed sample as shown in Fig. 7. This essentially accounts for the ITR $\left(1.08 \times 10^{-7} \mathrm{~m}^{2} \mathrm{~K} / \mathrm{W}\right)$ being much higher than that $\left(0.2 \times 10^{-7} \mathrm{~m}^{2} \mathrm{~K} / \mathrm{W}\right)$ of the VHPed composite. Note that the average ITR is derived from the measured TC of the composite by using the DEM scheme [15]. It has been found that the heterogeneity in interfacial configurations is present in the carbon fiber/AI composites fabricated by SPS in various pulse conditions [32]. This phenomenon can also be attributed to the above mentioned sintering mechanisms.

\subsection{Demonstration of macroscopic thermal gradients in rapid heating-cooling mode generated during SPS}

At the laboratory scale, satisfactory evaluation of the heterogeneous microstructural features inside the diamond/AI composite sample has often been carried out by statistical SEM or TEM examinations using the standard sample dimension being convenient for TC measurement by laser flash technique, i.e. with the diameters of around 10 or $12.7 \mathrm{~mm}$ and the height of several $\mathrm{mm}$. However, when the end product of such a composite is used as the electronic package material for applications in GaN RF power transistors, laser diodes and package LEDs, etc., at least one dimensional size in the range several tens of micrometers is required to be compatible with that of targeted devices. Despite its importance from the practical point of view, this work has not been reported in MMCs in the literature and, should allow our estimation of microstructure heterogeneity to extend from the micrometer scale as characterized by SEM (Fig. 7) up to the macroscopic scale. Originating from this motivation, further evaluation of the feasibility of SPS is carried out at the semi-industrial scale by producing a fully-dense disk sample with the dimension of $\varnothing 50 \times 10 \mathrm{~mm}$ (Fig. 11).

The difficulty to directly fulfil this task by using the diamond/Al composite results from sample surface preparation since the unique TIB technique is time consuming to prepare large flat surface for statistical SEM examination. In this case, the ODS FeAl alloy is used as an alternative and model material to validate the experiment since its grain structures, being significantly documented over the last decades, serve as an indicator of local temperature history due to different recrystallization responses of initial heavily-deformed nanostructure [8], [24], [43], [44], [45]. This part can also be regarded as an extension of our previous work where the SPS sintering and SEM/electron backscattering diffraction (EBSD) experimental conditions have been detailed in [24]. 

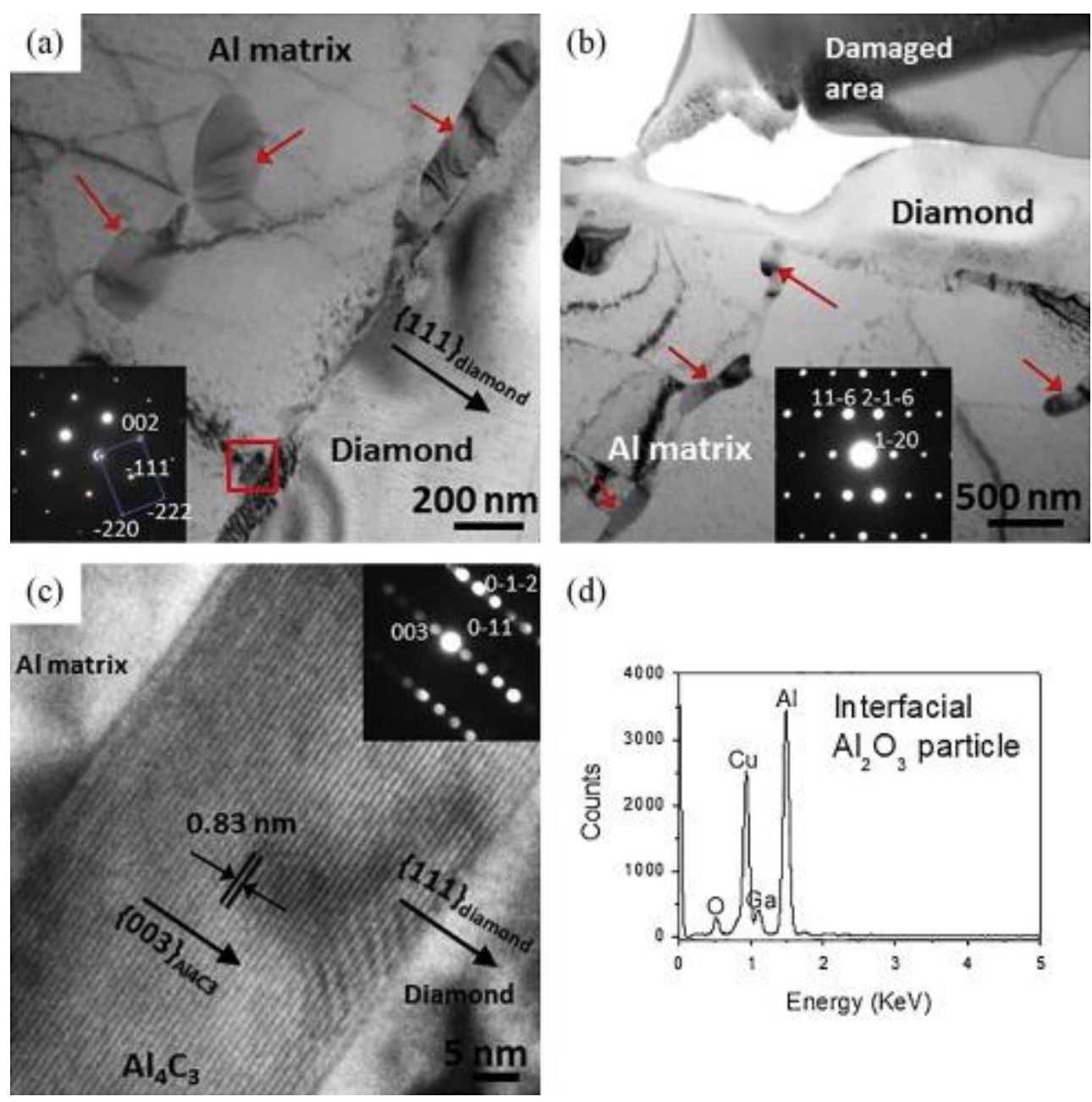

(d)

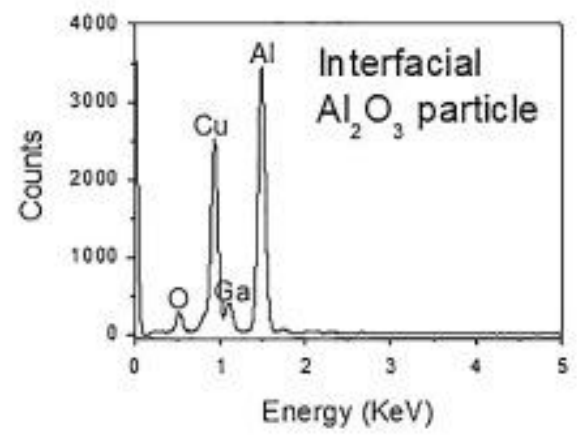

Fig. 8. (a) and (b) TEM BF images showing the diamond ${ }_{111} /$ /Al interface of the SPSed diamond (40 vol.\%)/Al composite in the as-prepared FIB sample, inset in (a) is the $\left[\begin{array}{lll}0 & 1 & 1\end{array}\right]$ ZAP of diamond side with adjusted orientation relationship with respect to image, while inset in (b) is [4 2 1] ZAP of one of the arrowed interfacial particles corresponding to the $\alpha-\mathrm{Al}_{2} \mathrm{O}_{3}$ phase (Trigonal, No. 167, ), (c) zoom-in lattice image of interfacial area in the box in (a) showing an $A_{4} C_{3}$ interfacial particle, inset in (c) is the [lll 100$] \mathrm{ZAP}$ of $\mathrm{Al}_{4} \mathrm{C}_{3}$ with adjusted orientation relationship with respect to image, and (d) typical EDX spectrum of the interfacial $\mathrm{Al}_{2} \mathrm{O}_{3}$; $\mathrm{Ga}$ and $\mathrm{Cu}$ peaks originate from effects of FIB preparation and sample holder, respectively. (For interpretation of the references to color in this figure legend, the reader is referred to the web version of this article.)
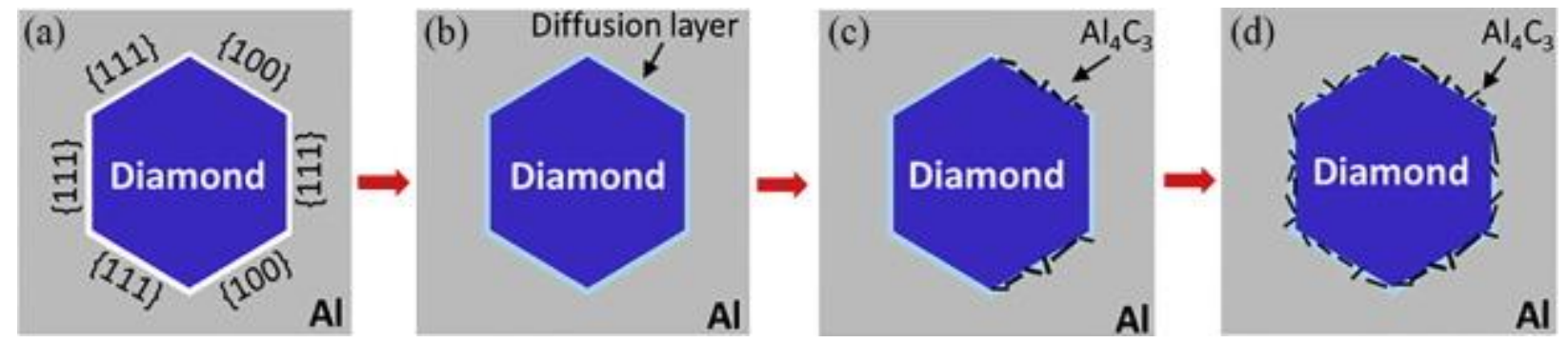

Fig. 9. Schematic drawing showing evolution of the diamond ${ }_{1111} /$ Al and diamond ${ }_{1100} /$ Al interfaces with temperature rise in thermodynamic equilibrium conditions, e.g., during VHP process: (a) non-bonded, (b) 'clean' quasi-diffusion-bonded, (c) partially reaction-bonded due to formation of interfacial $\mathrm{Al}_{4} \mathrm{C}_{3}$ at the diamond ${ }_{1100 /} / \mathrm{Al}$ interface and $(d)$ fully reaction-bonded interfaces. (For interpretation of the references to color in this figure legend, the reader is referred to the web version of this article.) 
Table 1

Thermal-physical properties of materials used for calculating ITR of the $\mathrm{Al} / \mathrm{Al}_{2} \mathrm{O}_{3} /$ diamond multi-interface (see Fig. 10).

\begin{tabular}{|c|c|c|c|c|c|c|}
\hline \multirow[t]{2}{*}{ Materials } & \multirow[t]{2}{*}{ Density $\left(\mathrm{kg} / \mathrm{m}^{3}\right)$} & \multirow[t]{2}{*}{$\mathrm{TC}(\mathrm{W} / \mathrm{m} \mathrm{K})$} & \multirow[t]{2}{*}{ Specific heat (J/kg K) } & \multicolumn{3}{|c|}{ Sound velocity $(\mathrm{m} / \mathrm{s})$} \\
\hline & & & & Average & Longitudinal & Traverse \\
\hline Diamond & 3520 & 1800 & 512 & $13,430[33]$ & - & - \\
\hline $\mathrm{Al}$ & 2700 & 230 & 895 & $3620[33]$ & - & - \\
\hline Crystallized $\mathrm{Al}_{2} \mathrm{O}_{3}$ & 3987 & $36[34]$ & 778 [35] & 7038 & 10,800 & $6350[36]$ \\
\hline Amorphous $\mathrm{Al}_{2} \mathrm{O}_{3}$ & 3200 & $1.5-1.8[37,38]$ & 1078 [39] & $7334[40]$ & & \\
\hline
\end{tabular}

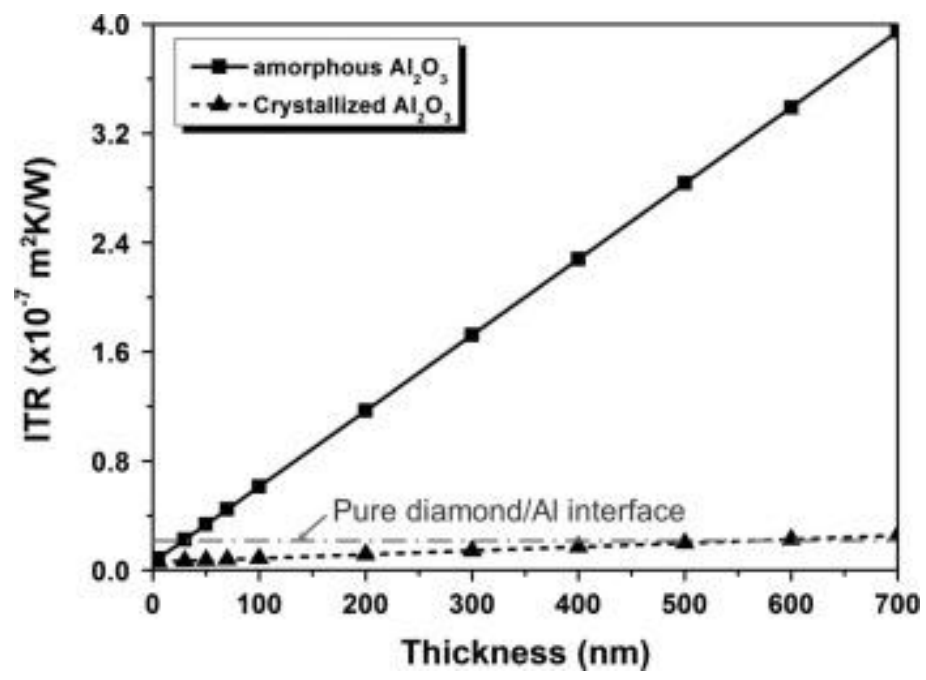

Fig. 10. Calculated ITR as a function of (crystallized and amorphous) $\mathrm{Al}_{2} \mathrm{O}_{3}$ interlayer thickness in the $\mathrm{Al}_{\mathrm{A}} \mathrm{Al}_{2} \mathrm{O}_{3} / \mathrm{diamond}$ multi-interface, dashed line showing ITR of the clean diamond/Al interface (i.e. without the additional $\mathrm{Al}_{2} \mathrm{O}_{3}$ interlayer in this case).

As monitored by the statistical average grain size and its distribution in Fig. 12, the radial and axial microstructural heterogeneities are confirmed to be maintained at the micrometer, observed by large grain size distributions (from nano-, ultrafine to micrometer sized recrystallized grains) in each OIM map, as well as at the macroscopic scales. For the latter, along the axial direction from sample center to edge spanning around $25 \mathrm{~mm}$, the average grain size is slightly reduced by around $3 \%$ from the area $A$ to $A^{\prime}$ and, by $8 \%$ from the area $B$ to $B^{\prime}$ (Fig. 11, Fig. 12). In addition, the upper part of sample has significantly larger average grain size by around $30 \%$ than in the lower part throughout the whole sample height (Fig. 11, Fig. 12). The temperature gradients due to current distribution together with radical heat losses through graphite die should be the main cause for these phenomena; the axial grain structure difference can further be attributed to the asymmetric positioning of the plungers in the die due to initial positioning or differences in sliding friction during the early stages of densification [5]. Hence, enough attention should be paid to reevaluate feasibility of the SPS technique for potential applications in MMCs. Regarding the key issue of interface engineering, the conventional VHP technique is definitively more feasible than the SPS technique to allow the unique -if any- diffusion-bonded interfacial state to be tailored, in the diamond/Al composite (at the micrometer scale) and in the SiC/Al composite (at the nanoscale) [21], in order to maximize the effectiveness of TC enhancement. In the SPS case, the TC enhancement is possible but less effective by only increasing the amount of diffusionbonded interface in the sample.

\section{Conclusions and remarks}

Densification of the diamond (40 and 50 vol.\%)/Al composites has been carried out by optimizing the SPS temperature in the range $540-560{ }^{\circ} \mathrm{C}$. The high relative density of around $97 \%$, being comparable with that of the VHPed counterpart, has been achieved in the SPSed diamond (40. vol.\%)/Al sample, while its measured TC of $330 \mathrm{~W} / \mathrm{m} \mathrm{K}$ is much lower than that of the VHPed sample of $475 \mathrm{~W} / \mathrm{m} \mathrm{K}$. Multiscale interfacial characterization by using XRD, SEM and (HR)TEM has revealed that at the 
micrometer scale the unique 'clean' diffusion-bonded interface has been achieved in the VHPed sample so that the effectiveness of TC enhancement is maximized. Comparatively, the results show that the SPSed sample presents a mixed bonding state including the non-bonded, 'clean' diffusion-bonded and reaction-bonded interfaces. The (radial and axial) thermal gradients generated during the SPS process, confirmed at the micrometer and macroscopic scales, account for such a bonding state which reduce the effectiveness of TC enhancement. Further, the interfacial crystallized $\mathrm{Al}_{2} \mathrm{O}_{3}$ particles present in the VHPed and SPSed samples seems not to play a negative role in interfacial bonding and ITR. Finally, from the technical point of view, the unusual characteristics involved in the SPS process should be reevaluated for producing specific MMCs for functional applications.
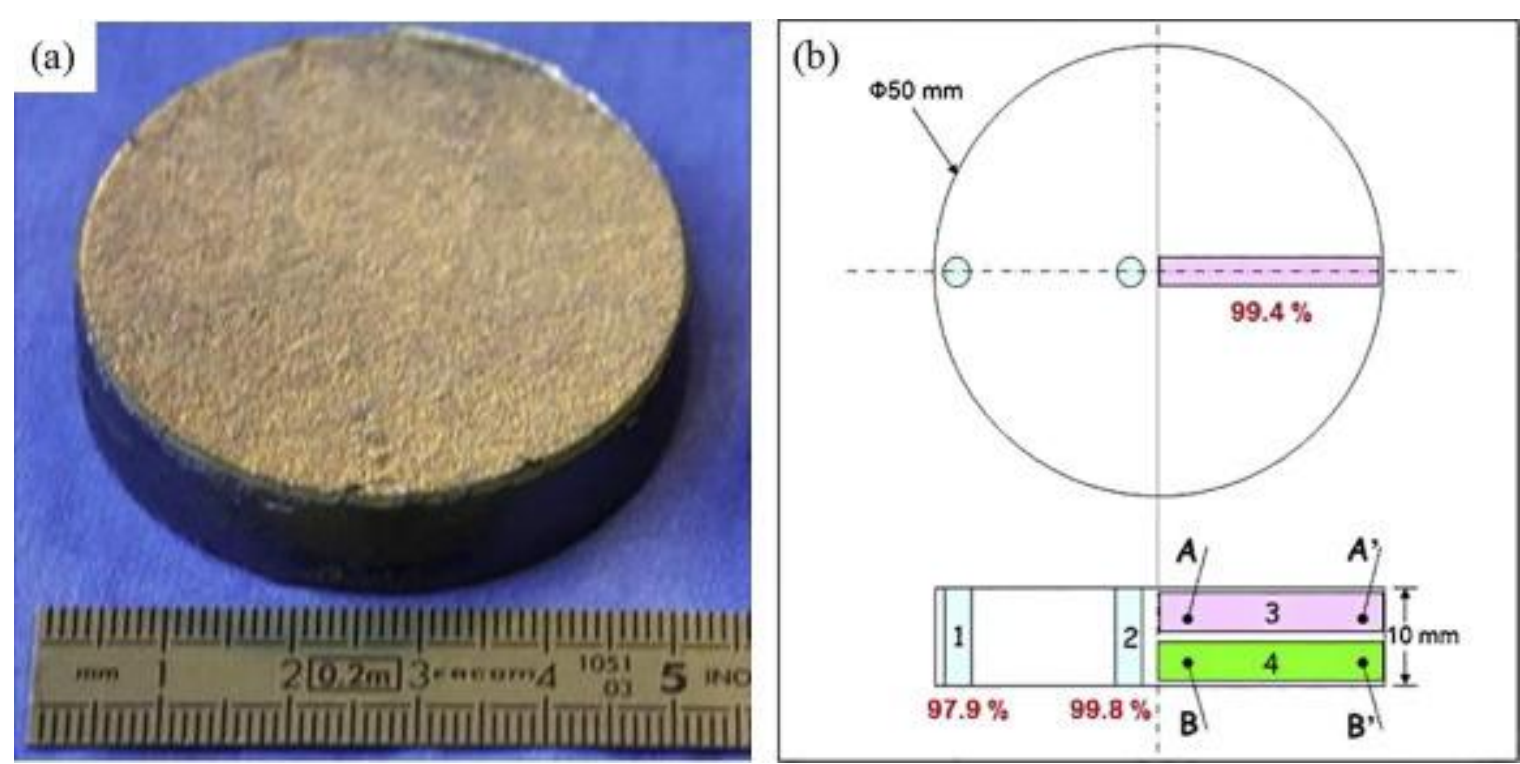

Fig. 11. (a) Photograph of the SPSed disk sample, with a dimension of $\emptyset 50 \times 10 \mathrm{~mm}$, obtained from milled nanocrystalline FeAl powder and (b) schematic drawing showing specific locations selected to evaluate macroscopic (radial and axial) heterogeneities by relative density and statistical grain size distribution. (For interpretation of the references to color in this figure legend, the reader is referred to the web version of this article.) 

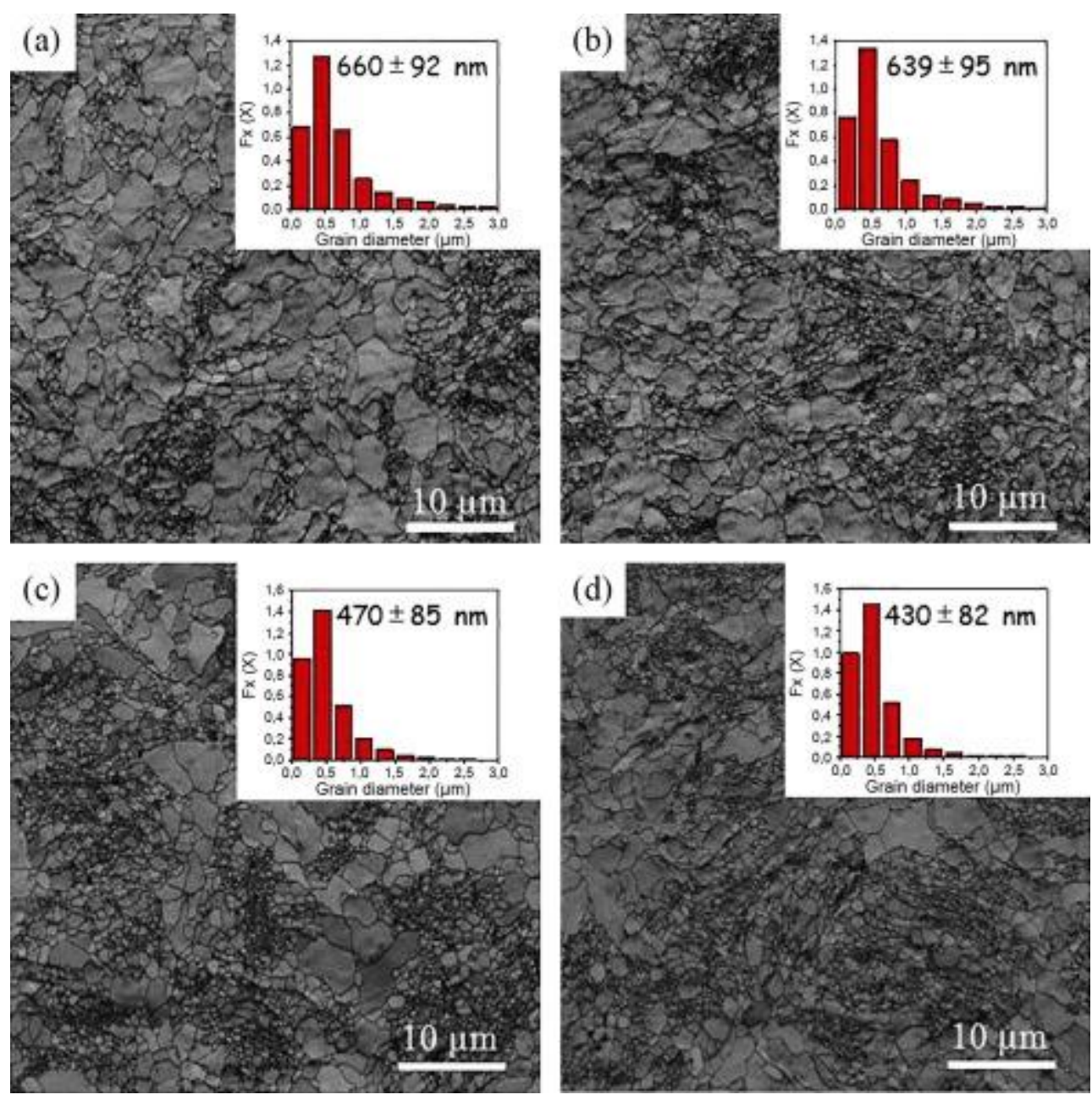

Fig. 12. Orientation imaging microscopy (OIM) maps of the SPSed ODS FeAl alloys sample, characterized by SEM/EBSD analysis showing large grain size distributions covering nanosized, sub-micrometer and micrometer grains in the locations namely (a) A; (b) A'; (c) B and (d) B' (see Fig. 11); insets are histograms of statistical grain size distributions. (For interpretation of the references to color in this figure legend, the reader is referred to the web version of this article.)

\section{Acknowledgement}

The authors would like to acknowledge the financial support of the travel funding BQR (No. R8DIV AUE) provided by Université Lille 1, the open foundation from the State Key laboratory of Metal Matrix Composites, Shanghai Jiao Tong University, the National Basic Research Program (973 Program) (No. 2012CB619600), the National Natural Science Foundation (Nos. 51131004, 51401123, 51511130038) and the China Postdoctoral Science Foundation (Grant No. 2014M561469) for Dr. Z.Q. Tan. This work has partially been funded by the project of the Ministère Français de la Recherche (Convention No.03K558). Dr. W.G. Grünewald (Leica Microsystems, Germany) is also thanked for the assistance of surface preparation.

\section{References}

1. Z.A. Munir, U. Anselmi-Tamburini, M. Ohyanagi. The effect of electric field and pressure on the synthesis and consolidation of materials: a review of the spark plasma sintering method. $J$ Mater Sci, 41 (2006), pp. 763-777.

2. Z.A. Munir, D.V. Quach, M. Ohyanagi. Electric current activation of sintering: a review of the pulsed electric current sintering process. J Am Ceram Soc, 94 (2011), pp. 1-19. 
3. W. Chen, U. Anselmi-Tamburini, J.E. Garay, J.R. Groza, Z.A. Munir. Fundamental investigations on the spark plasma sintering/synthesis process: I. Effect of dc pulsing on reactivity. Mater Sci Eng A, 394 (2005), pp. 132-138.

4. U. Anselmi-Tamburini, J.E. Garay, Z.A. Munir. Fundamental investigations on the spark plasma sintering/synthesis process: III. Current effect on reactivity. Mater Sci Eng A, 407 (2005), pp. 2430 .

5. U. Anselmi-Tamburini, S. Gennari, J.E. Garay, Z.A. Munir. Fundamental investigations on the spark plasma sintering/synthesis process: II. Modeling of current and temperature distributions. Mater Sci Eng A, 394 (2005), pp. 139-148.

6. M. Kubota, B.P. Wynne. Electron backscattering diffraction analysis of mechanically milled and spark plasma sintered pure aluminium. Scripta Mater, 57 (2007), pp. 719-722.

7. B. Srinivasarao, K. Oh-ishi, T. Ohkubo, T. Mukai, K. Hono. Synthesis of high-strength bimodally grained iron by mechanical alloying and spark plasma sintering. Scripta Mater, 58 (2008), pp. 759-762.

8. T. Grosdidier, G. Ji, S. Launois. Processing dense hetero-nanostructured metallic materials by spark plasma sintering. Scripta Mater, 57 (2007), pp. 525-528.

9. T.T. Sasaki, T. Mukai, K. Hono. A high-strength bulk nanocrystalline Al-Fe alloy processed by mechanical alloying and spark plasma sintering. Scripta Mater, 57 (2007), pp. 189-192.

10. M. Kubota, P. Cizek, W.M. Rainforth. Properties of mechanically milled and spark plasma sintered Al-15 at. \% MgB 2 composite materials. Compos Sci Technol, 68 (2008), pp. 888-895.

11. Y. Long, T. Wang, H.Y. Zhang, X.L. Huang. Enhanced ductility in a bimodal ultrafine-grained Ti-6Al-4V alloy fabricated by high energy ball milling and spark plasma sintering. Mater Sci Eng A, 608 (2014), pp. 82-89.

12. Z.Y. Li, Z. Lu, R. Xie, C.Y. Lu, C.M. Liu. Effect of spark plasma sintering temperature on microstructure and mechanical properties of 14Cr-ODS ferritic steels. Mater Sci Eng A, 660 (2016), pp. 52-60.

13. A. Luedtke. Thermal management materials for high-performance applications. Adv Eng Mater, 6 (2004), pp. 142-144.

14. W.B. Johnson, B. Sonuparlak. Diamond/Al metal matrix composites formed by the pressureless metal infiltration process. J Mater Res, 8 (1993), pp. 1169-1173.

15. Z.Q. Tan, Z.Q. Li, G.L. Fan, Q. Guo, X.Z. Kai, G. Ji, L.T. Zhang, D. Zhang. Fabrication of diamond/aluminum composites by vacuum hot pressing: process optimization and thermal properties. Composites Part B, 47 (2013), pp. 173-180.

16. Z.Q. Tan, Z.Q. Li, G.L. Fan, Q. Guo, X.Z. Kai, G. Ji, L.T. Zhang, D. Zhang. Enhanced thermal conductivity in diamond/aluminum composites with a tungsten interface nanolayer. Mater Des, 47 (2013), pp. 160-166.

17. K. Mizuuchi, K. Inoue, Y. Agari, M. Sugioka, M. Tanaka, T. Takeuchi, M. Kawahara, Y. Makino. Thermal conductivity of diamond particle dispersed aluminum matrix composites fabricated in solid-liquid co-existent state by SPS. Composites Part B, 42 (2011), pp. 1029-1034.

18. X.B. Liang, C.C. Jia, K. Chu, H. Chen, J.H. Nie, W.J. Gao. Thermal conductivity and microstructure of $\mathrm{Al} /$ diamond composites with $\mathrm{Ti}$-coated diamond particles consolidated by spark plasma sintering. J Compos Mater, 46 (2016), pp. 1127-1136.

19. I.E. Monje, E. Louis, J.M. Molina. Aluminum/diamond composites: a preparative method to characterize reactivity and selectivity at the interface. Scripta Mater, 66 (2012), pp. 789-792.

20. G. Ji, Z.Q. Tan, R. Shabadi, Z.Q. Li, W.G. Grünewald, A. Addad, D. Schryvers, D. Zhang. Triple ion beam cutting of diamond/Al composites for interface characterization. Mater Charact, 89 (2014), pp. 132-137. 
21. Z.Z. Chen, Z.Q. Tan, G. Ji, G.L. Fan, D. Schryers, Q.B. Ouyang, Z.Q. Li. Effect of interface evolution on thermal conductivity of vacuum hot pressed SiC/Al composites. Adv Eng Mater, 17 (2015), pp. 1076-1084.

22. Z.Q. Tan, Z.Q. Li, D.B. Xiong, G.L. Fan, G. Ji, D. Zhang. A predictive model for interfacial thermal conductance in surface metallized diamond aluminum matrix composites. Mater Des, 55 (2014), pp. 257-262.

23. H. Feng, J.K. Yu, W. Tan. Microstructure and thermal properties of diamond/aluminum composites with TiC coating on diamond particles. Mater Chem Phys, 124 (2010), pp. 851-855.

24. G. Ji, F. Bernard, S. Launois, T. Grosdidier. Processing conditions, microstructure and mechanical properties of hetero-nanostructured ODS FeAl alloys produced by spark plasma sintering. Mater Sci Eng A, 559 (2013), pp. 566-573.

25. S. Kleiner, F.A. Khalid, P.W. Ruch, S. Meier, O. Beffort. Effect of diamond crystallographic orientation on dissolution and carbide formation in contact with liquid aluminium. Scripta Mater, 55 (2006), pp. 291-294.

26. P.W. Ruch, O. Beffort, S. Kleiner, L. Weber, P.J. Uggowitzer. Selective interfacial bonding in $\mathrm{Al}(\mathrm{Si})$-diamond composites and its effect on thermal conductivity. Compos Sci Technol, 66 (2006), pp. 2677-2685.

27. G. Ji, Z.Q. Tan, Y.G. Lu, D. Schryers, Z.Q. Li, D. Zhang. Heterogeneous interfacial chemical nature and bonds in a W-coated diamond/Al composite. Mater Charact, 112 (2016), pp. 129-133.

28. C. Zhou, G. Ji, Z. Chen, M.L. Wang, A. Addad, D. Schryvers, H.W. Wang. Fabrication, interface characterization and modeling of oriented graphite flakes/Si/Al composites for thermal management applications. Mater Des, 63 (2014), pp. 719-728.

29. I.E. Monje, E. Louis, J.M. Molina. Optimizing thermal conductivity in gas-pressure infiltrated aluminum/diamond composites by precise processing control. Composites Part A, 48 (2013), pp. 9-14.

30. Z.F. Che, Y. Zhang, J.W. Li, H.L. Zhang, X.T. Wang, C. Sun, J.G. Wang, M.J. Kim. Nucleation and growth mechanisms of interfacial $\mathbf{A l}_{\mathbf{4}} \mathbf{C}_{\mathbf{3}}$ in $\mathbf{A l}$ /diamond composites. $\mathrm{J}$ Alloys Compd, 657 (2016), pp. 81-89.

31. H.N. Yang, M.Y. Gu, W.J. Jiang, G.D. Zhang. Interface microstructure and reaction in Gr/Al metal matrix composites. J Mater Sci, 31 (1996), pp. 1903-1907.

32. G. Lalet, H. Kurita, T. Miyazaki, A. Kawasaki, J.F. Silvain. Microstructure of a carbon fiberreinforced aluminum matrix composite fabricated by spark plasma sintering in various pulse conditions. J Mater Sci, 49 (2014), pp. 3268-3275.

33. R. Lübbers, H.F. Grünsteudel, A.I. Chumakov, G. Wortmann. Density of phonon states in iron at high pressure. Science, 287 (2000), pp. 1250-1253.

34. X.W. Wang, X.F. Xu, S.U.S. Choi. Thermal conductivity of nanoparticle-fluid mixture. J Thermophys Heat Trans, 13 (1999), pp. 474-480.

35. P.F. McMillan, N.L. Ross. Heat capacity calculations for $\mathrm{Al}_{2} \mathbf{O}_{3}$ corundum and $\mathrm{MgSiO}_{3}$ ilmenite. Phys Chem Miner, 14 (1987), pp. 225-234.

36. L.R. Rossi, W.G. Lawrence. Elastic properties of oxide solid solutions: the system $\mathrm{Al}_{2} \mathbf{O}_{3}-\mathrm{Cr}_{2} \mathrm{O}_{3}$. J Am Ceram Soc, 53 (1970), pp. 604-608.

37. I. Stark, M. Stordeur, F. Syrowatka. Thermal conductivity of thin amorphous alumina films. Thin Solid Films, 226 (1993), pp. 185-190.

38. A. Cappella, J.L. Battaglia, V. Schick, A. Kusiak, A. Lamperti, C. Wiemer, B. Hay. High temperature thermal conductivity of amorphous $\mathrm{Al}_{2} \mathrm{O}_{3}$ thin films grown by low temperature ALD. Adv Eng Mater, 15 (2013), pp. 1046-1051. 
39. V.V. Hoang. Molecular dynamics study on structure and properties of liquid and amorphous $\mathbf{A l}_{2} \mathbf{O}_{3}$. Phys Rev B, 70 (2004), p. 134204.

40. P. Vashishta, R.K. Kalia, A. Nakano, J.P. Rino. Interaction potentials for alumina and molecular dynamics simulations of amorphous and liquid alumina. J Appl Phys, 103 (2008), p. 083504.

41. S. Fromentin. Glenn Elert (Ed.), Resistivity of carbon diamond, The Physics Factbook (2004). [Retrieved 30 December 2011].

42. P.D. Desai, H.M. James, C.Y. Ho. Electrical resistivity of aluminum and manganese. J Phys Chem Ref Data, 13 (1984), pp. 1131-1172.

43. G. Ji, T. Grosdidier, N. Bozzolo, S. Launois. The mechanisms of microstructure formation in a nanostructured oxide dispersion strengthened FeAl alloy obtained by spark plasma sintering. Intermetallics, 15 (2007), pp. 108-118.

44. R. Baccino, D. San Filippo, F. Moret, A. Lefort, G. Webb. Proceedings of the PM'94, Powder Metallurgy World Congress, Paris, June 1994, vol. II, Editions de Physique, Les Ulis (1994), p. 1239.

45. T. Grosdidier, E. Suzon, F. Wagner. Primary recrystallization in an ODS FeAl alloy: an effective way to modify texture and microstructure. Intermetallics, 12 (2004), pp. 645-654. 